\title{
FLAGSHIPSPECIES
}

\section{Lemurs - Ambassadors for Madagascar}

Urs Thalmann ${ }^{1, " 1}$

\section{ABSTRACT}

In this short article on lemurs I give a concise introduction for non-specialists to these conspicuous and unique animals on the island of Madagascar.

\section{INTRODUCTION}

Madagascar has long been known for its exquisite wildlife. It has been identified as a Megadiversity country and "Hottest Hotspot" for biodiversity conservation (Meyers et al. 2000 Mittermeier et al. 2005) due to the combination of extraordinary high diversity and extreme degree of threat. Lemurs, a natural group of primates endemic to Madagascar, are possibly the most conspicuous and most widely known wildlife of Madagascar. In this article, written for a non-specialist audience, I try to situate these mammals in a wider context to shed light on (i) their biological position and diversity, (ii) some biological pecularities, and (iii) the important role they may play for Malagasy conservation and development.

\section{MADAGASCAR: A MEGADIVERSITY COUNTRY}

Madagascar is located almost entirely within the tropics. This geographic location with its typical wind regime (trade winds, monsoon. Donque 1975), combined with a north-south mountain chain reaching heights up to $2000 \mathrm{~m}$ and more allows for year long orographic precipitation on the eastern side, and prolonged dry periods with a distinct rainy season in the wide western lowlands. Combined with the long geological isolation from large continental landmasses but occasional non-synchronized colonisation events by mammals this provides the coarse scenario for the evolution of Madagascar's mammal wildlife (Goodman and Beanstead 2003, for a comprehensive overview). Due to this particular combination (geographic position, relief, geology, long isolation, occasional colonization) the fauna of Madagascar (biodiversity in general) evolved tremendous endemism.

\section{MADAGASCAR'S MAMMAL COMPOSITION}

On a high systematic level, eight placental mammal orders are present on Madagascar (without cetaceans), whereas 15 are present in continental Africa, 15 in Asia, and 11 in the Americas out of 19 orders globally (Figure 1). The composition is, however, very special. There are on average less genera per

I ANTHROPOLOGICAL INSTITUTE, UNIVERSITY ZÜRICH-IRCHEL, SWITZERLAND

\author{
Anthropological Institute \\ University Zurich-Irchel \\ Winterthurerstrasse 190 \\ $\mathrm{CH}-8057$ Zurich, Switzerland \\ Phone: +41446354192 \\ Fax: +41-44-635 6804 \\ E-mail: uthal@aim.unizh.ch
}

animal order in Madagascar (8.1 genera/order) than on other continents. One order of Malagasy mammals, Bibymalagasia, is entirely restricted to Madagascar and went extinct only relative recently (MacPhee 1994) along with artiodactyle pygmy hippos and other large vertebrates (Burney 2004). Within Malagasy mammals, the mammal order primates clearly stands out with the endemic lemurs. The lemurs are the most diverse mammal group on the generic level, and Madagascar is the only place where primates genera are the dominant group overall. On a global scale primates rank 5th behind rodents, bats, carnivores, and even-toed hoofed mammals.

\section{MADAGASCAR: A HOTSPOT FOR CONSERVATION}

A biodiversity hotspot is a region that contains at least $0.5 \%$ (or 1,500) of the world's 300,000 plant species as endemics and has lost $70 \%$ or more of its primary vegetation. Madagascar harbours around 12,000 plant species of which about 9,700 or $3.2 \%$ of the world's plant species are endemic. An enormous $90 \%$ of the primary vegetation has been lost (Myers et al. 2000). This qualifies Madagascar obviousely as a biodiversity hotspot. Additionally, the consideration of five key factors, endemics and endemic species/area ratios for both plants and vertebrates and habitat loss ranks Madagascar in all figures among the top ten hotspots, along with the Philippines and Sundaland. Hence these regions are also called "hottest hotspots" (Myers et al. 2000). How did Madagascar achieve this position? Madagascar was one of the last great habitable land masses settled by humans. According to the comprehensive review by Burney et al. (2004), multiple points of evidence date the earliest presence of humans at ca. $350 \mathrm{yr}$ BC. A decline in megafauna at around 230-410 AD is followed by large increases in charcoal particles in sediments signalling increased human impact on the landscape. When Madagascar was discovered by Europeans in 1500, almost all of the Malagasy megafaua-pygmy hippos, elephant birds, giant tortoises, large lemurs -had already disappeared. This was the result of the synergistic combination of human impact, nonlinear natural responses and environmental change, population fragmentation, and local extirpation (Burney et al. 2004). Today, the same negative synergies of resource overutilization, fire-mediated vegetation change, and biological invasion combined with an enormously growing

॥ JANE GOODALL INSTITUTE SWITZERLAND 


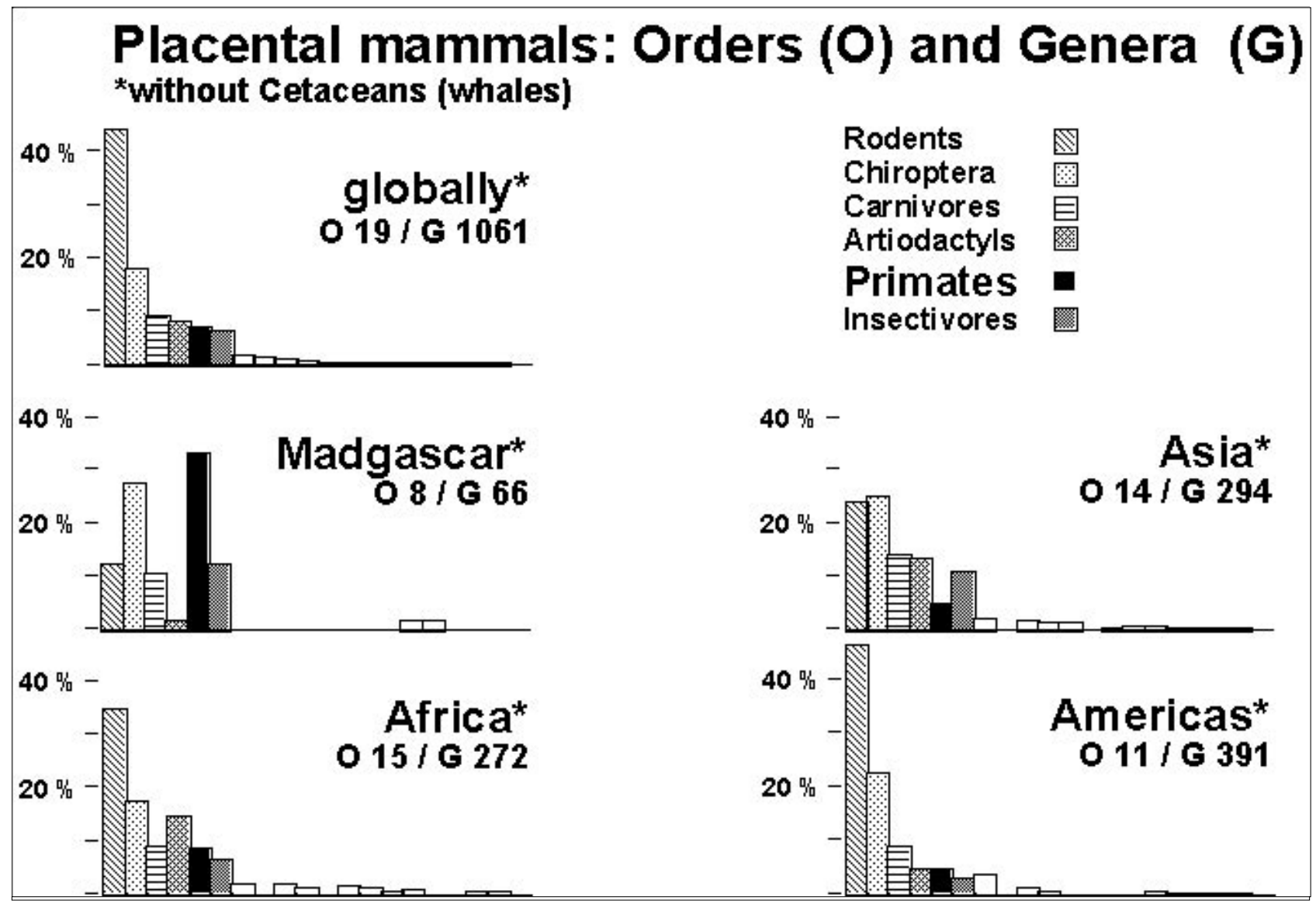

FIGURE 1. Comparative composition of Madagascar's mammal fauna. Only in Madagascar are (non-human) primates the dominant order in number of genera. Based on Nowak (1999).

population continue, pulling smaller lemur species and a host of other organisms into the extinction vortex.

\section{WHAT ARE LEMURS?}

Lemurs (Lemuriformes) are one of the six natural groups of primates and occur only in Madagascar (Figure 2). On the nearby Comoros they have been introduced from Madagascar (Pastorini et al. 2003). The Afro-Asian Loriformes (lorises and bushbabies) are the closest relatives. Together these primates constitute the strepsirrhine group that encompasses primates with a "wet" nose and other common characteristics. The name refers to the morphology of the nose with an outer rhinarium and a midline cleft, as for example in cats and dogs. Conversely, Southeast Asian tarsiers, New World Monkeys, Afro-Asian Old World Monkeys, apes and humans are considered as a group apart, the haplorrhines. There are several characteristics that distinguish strepsirrhines and haplorrhines as well as the different groups. The eye of most lemurs, the lorises and galagos, for example, have a reflective layer in the eye as have many other mammals. This reflecting layer facilitates finding them at night. This layer is not developed in haplorrhine primates. Strepsirrhine and haplorrhine primates are distinguished by many other morphological, physiological and anatomical characters. These are not presented here but can be found in text books on primatology (e.g., Fleagle 1999).

Today, 15 lemur genera representing 5 zoological families still survive, whereas at least 8 genera representing 3 families have disappeared in pre-historic time. A major role has been attributed to the arrival of human settlers on the island as trigger for the extinction of these lemurs (Burney et al. 2004). Large, diurnal lemurs were especially prone to extinction. Today, the largest surviving diurnal lemurs reach a body mass of approximately $7.5 \mathrm{~kg}$ (eastern Propithecus and Indri). All extinct diurnal lemur genera had a higher body mass, the largest may have reached a body mass of 150-200 kg (Figure 3).

\section{HOW MANY LEMUR SPECIES EXIST?}

The number of lemur species has dramatically increased over the past 15 years (Figure 4). Whereas Mittermeier et al. (1994) counted 32 species in the first edition of their lemur guide, this number has more than doubled. My current compilation reaches 71 species (based on Mittermeier et al. 2006, Andriaholinirina et al., 2006, Louis et al. 2006), and further descriptions of new species are immanent. This development has several, mutually not exclusive, reasons: i) discovery and characterization of new species, ii) resurrection of synonyms, and iii) the application of new species concepts.

i) Since the beginning of the new millenium, 15 new lemur species have been described. Most of them were formerly lumped with closely resembling species and/or not recognized as distinct species (Avahi spp., Cheirogaleus spp., Lepilemur spp. Figure 5), Microcebus spp., Mirza zaza). ii) Accompanying such research efforts, nine old names have been resurrected from synonymy based on new information from the field and museum work (e.g. Cheirogaleus spp., Microcebus spp.), including two subspecies of the diurnal Varecia variegata $(V$. v. editorum and $V$. 


\section{Natural Groups of Primates}

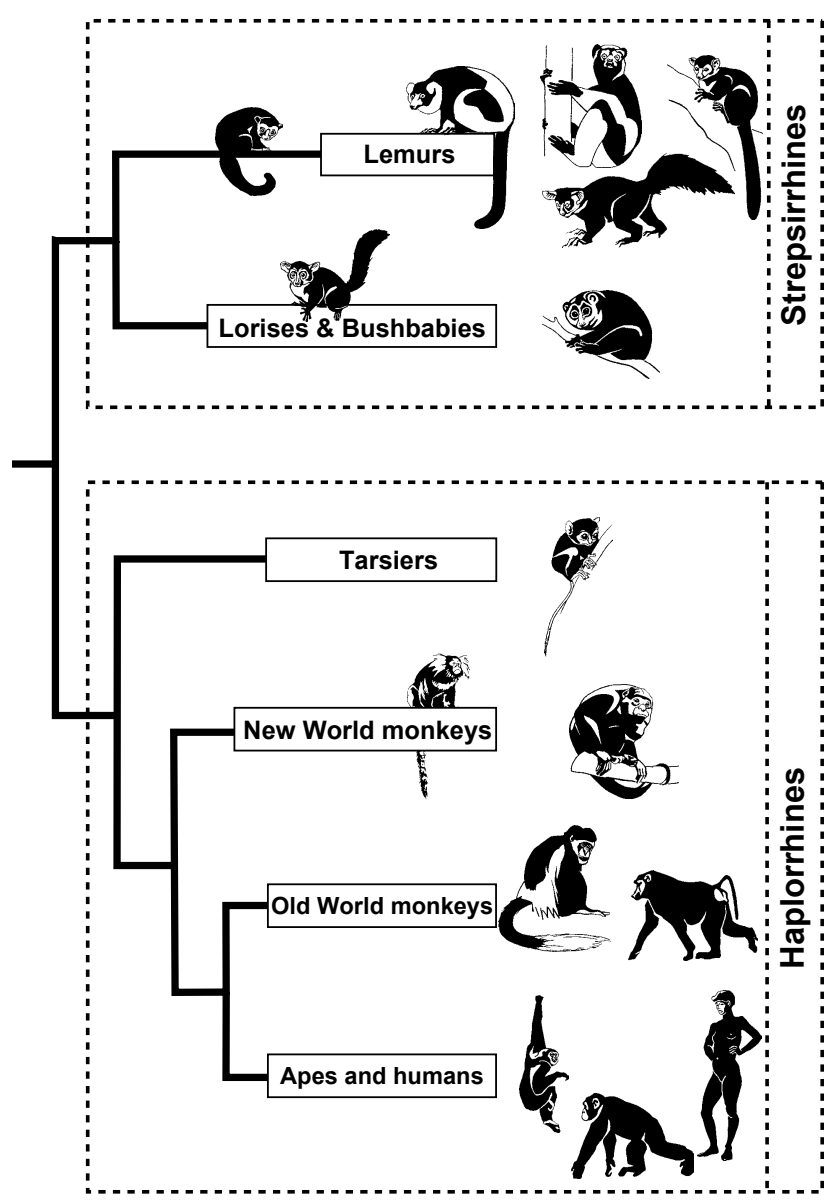

FIGURE 2. Natural groups of primates. The zoological order primates is grouped into strepsirrhine primates with lemurs, lorises and bushbabies on the one hand, and haplorrhine primates with tarsiers, New and Old World Monkeys, apes and humans on the other hand. Drawings by Lucrezia Bieler.

v. subcincta). iii) Most influential was the application of a different species concept, the Phylogenetic Species Concept from Cracraft (1983). This led to the recognition of many former subspecies as species (for a detailed review see Thalmann, in press).

\section{PARTICULARITIES IN LEMURS}

Lemurs are not only endemic to Madagascar they also show interesting characteristics which are very particular amongst primates and even among mammals. This makes lemurs scientifically especially interesting for comparative studies with other primates in other regions.

Unfortunately, only the smaller lemurs survived into our days, but once the lemur radiation covered a body mass range from $30 \mathrm{~g}$ (Microcebus berthae) to $150-200 \mathrm{~kg}$ (Archaeoindris). With $30 \mathrm{~g}$ Microcebus berthae, Madame Berthe's mouse lemur is the smallest primate world wide. Some of the smaller lemurs belonging to the family cheirogaleidae are able to reduce their metabolism and enter torpor or hibernation. Cheirogaleus medius, the fat-tailed dwarf lemur for example, spends several months during the austral winter to overcome the dry period in the dry portions of Madagascar where it occurs.

Most of today's surviving lemur species are nocturnal, in line with their usually small body size. In general, nocturnal primates are smaller than diurnal primates (Martin 1990). However, some diurnal species remain such as the Indri, Propithecus and Vare-

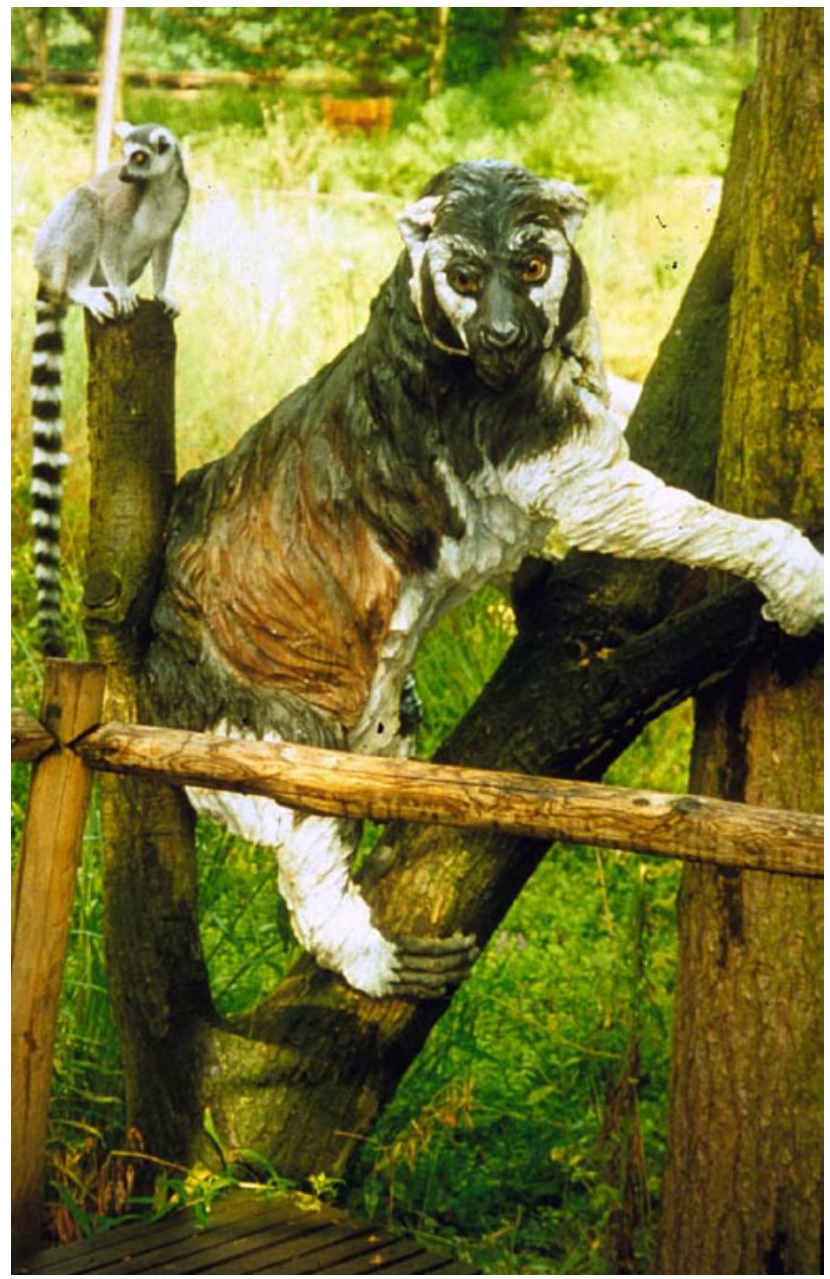

FIGURE 3. A ringtailed lemur in comparison with an extinct lemur of the genus Megaladapis in Apenheul Zoo, the Netherlands. Photo: Jenny Pastorini.

cia. A third activity pattern - cathemerality - is present in many species of the genus Eulemur (e.g., Eulemur mongoz). These lemurs have activity peaks distributed over the entire daily 24 hr cycle, modified according to season (Curtis et al. 2006).

Particularly interesting is the social organization of some lemurs. On average, they live in smaller groups than monkeys. In many species, females are dominant over males, which is unusual among primates. Also, an unusually high portion of the surviving lemurs live in pairs with their offspring. Indeed, based on investigations of nocturnal lemurs it has been shown that the ancestral social organization in primates was not a kind of harem. It was most likely either a dispersed multifemale/ multimale organization or they were organized in dispersed pairs (Müller and Thalmann 2000). Lemurs are usually seasonal breeders with seasonal birthpeaks. Offspring are carried from birth by their mothers in many species with singletons. Other species - mostly nocturnal smaller lemurs - have litter sizes of up to 4 and build nests for their offsprings. The nocturnal sportive lemurs usually cache their single offsprings while adults are foraging. The diurnal Varecia is an exception among diurnal lemurs and cathemeral lemurs because they usually have more than one offspring and leave them in nests until they can follow their mother.

Lemurs cover a wide range of dietary regimes from primarily folivores to frugivores and omnivores. Some are highly special- 


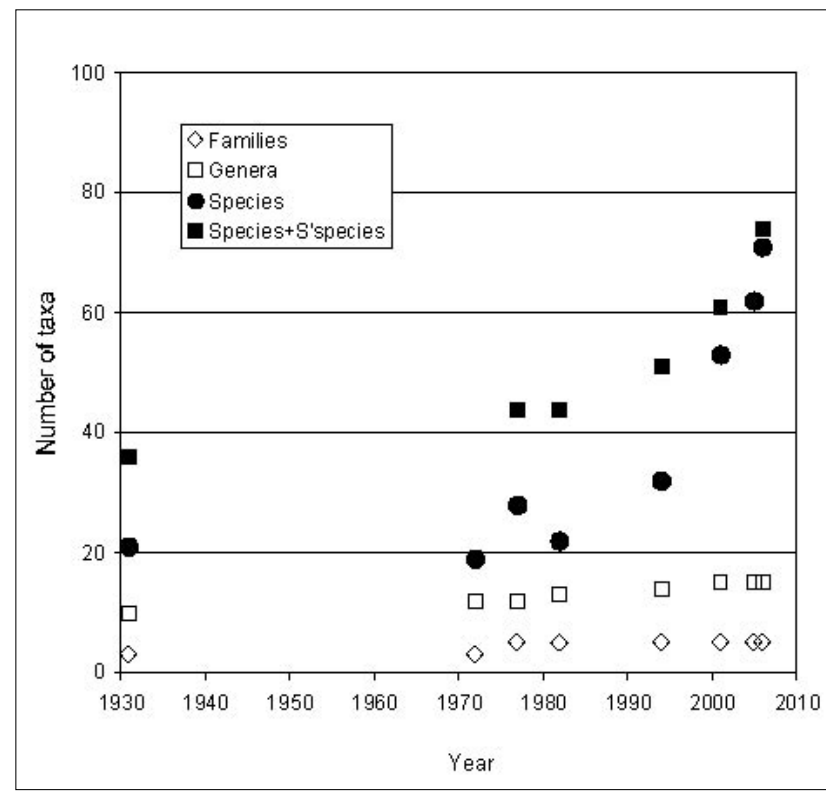

FIGURE 4. Number of lemur taxa from 1931 to 2006. Based on Schwarz (1931), Martin (1972), Petter et al. (1977), Tattersall (1982), Mittermeier et al. (1994), Groves (2001), Global Mammal Assessment (2005 unpubl.), Mittermeier et al. (2006), Andriaholinirina et al. (2006), Louis et al. (2006).

ized, others exhibit a broader adaptable regime. Specialists are for example fork-marked lemurs (Phaner furcifer) prefering gum (plant exudates), the woolly and sportive lemurs feeding almost completly on leaves and buds, and gentle or bamboo lemurs feeding on different parts of bamboo depending on the species. Especially notable among the gentle lemurs is the Alaotran gentle lemur. This lemur lives only around Lake Alaotra in the reed and Papyrus region. This habitat makes this lemur unique among primates world-wide but also makes it one of the most threatened, because reed beds around Lake Alaotra are still decreasing due to human activities.

Today's surviving lemurs are still widely distributed in Madagascar where suitable habitat remains and specific ecological requirements are met. Lemurs live almost exclusively in different kinds of forests, evergreen rainforests, dry deciduous western forests and southern spiny bush vegetation. Some species survive in secondary vegetation and in plantations. However, most of the forests are considerably threatened and fragmented, and with them many lemur species suffer from environmental pressure. The Global Mammal Assessment workshop for Madagascar organized by the International Union for the Conservation of Nature (IUCN) and Conservation International $(\mathrm{Cl})$ revealed that two third of all species are threatened (Figure 6) according to IUCN categories (IUCN, 2001). Twelve percent (8 species) were classified in the Critically Endangered category, the highest threat category, and $28 \%$ (17 species) in the Endangered category. On a world wide scale, four of these lemurs (Greater bamboo lemur, White-collared lemur, Silky sifaka, Perrier's sifaka) rank in the top 25 most endangered primates (Mittermeier et al. 2005).

\section{THE ROLE OF LEMURS}

Despite the fact that a third of all lemurs, including the largest species reaching up to $200 \mathrm{~kg}$, have already disappeared, the remaining lemurs are still the most diverse

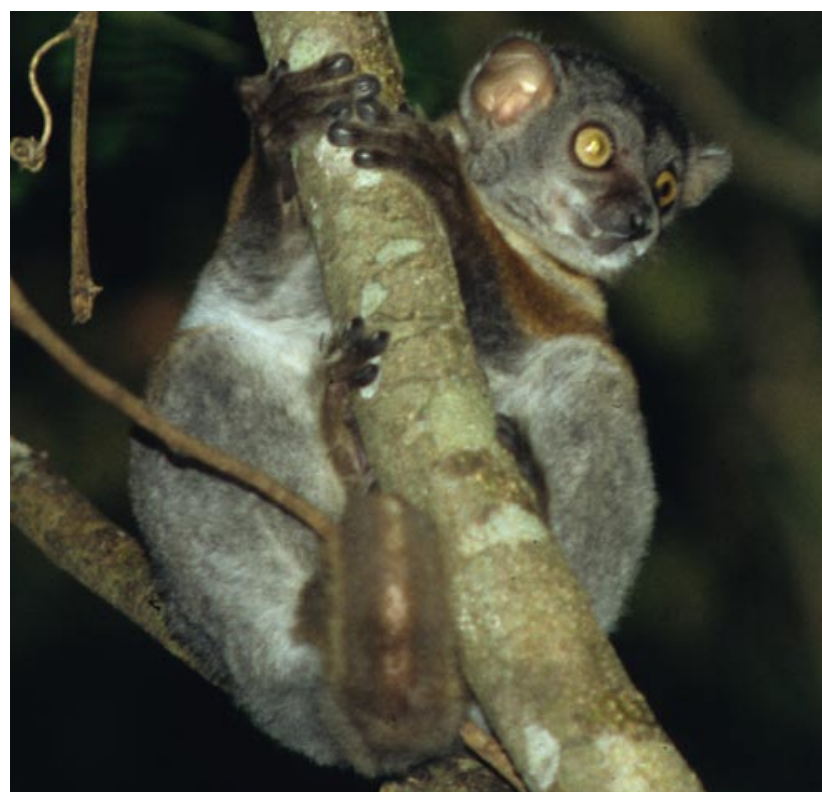

FIGURE 5. Lepilemur randrianasoli. This sportive lemur was fomerly thought to be $L$. edwardsi, then attributed to $L$. ruficaudatus, and has recently been identified as new species based on genetic studies (Andriaholinirina et al., 2006).

mammal group of Madagascar. Biologically they constitute an integral and important part of Madagascar's natural heritage and remaining ecosystems. As a primate group endemic to Madagascar they constitute a unique part of the world's natural heritage and a unique part of humankind's natural history. Being mostly forest dwelling animals they may serve as ambassadors for the forests of Madagascar and the whole wildlife in these forests all over the island where it remains. Lemur conservation equals forest conservation. Unique as lemurs are biologically, diverse, fluffy and sympathetic, they may serve as flagship species for the whole island. With regionally occurring endemic species they may even serve as flagships for different regions within Madagascar (e.g. the Alaotran gentle lemur. Durbin 1999). In addition, lemurs are ideally suited for many kinds of different research and favoured subjects by researchers from the North. This attractiveness can also help to find funds for research by Malagasy students. Acquired skills in natural sciences and research are transferable to other domains of daily importance, and should not be considered purely academic. Indeed, a rapidly growing community of Malagasy students and researchers are integrated in smaller and larger projects together with partners from the North. However, lemurs should not be seen merely as utilities for the development of Malagasy society. Lemurs are part of the aesthetics that nature has, and cannot be valued in simple monetary terms. As unique as lemurs are, most of Madagascar's wildlife is. However, the aesthetic of scorpions, snakes, insects - as unique as they are too - is more difficult to explain and these animals are less attractive for most humans. Protecting and conserving lemurs will help to protect a plethora of other species as collateral effect. Because lemur conservation is forest conservation, the protection of lemurs also helps to grant important services by forests, such as reduced erosion, clear and sustainable water proliferation - a better life for humans. 


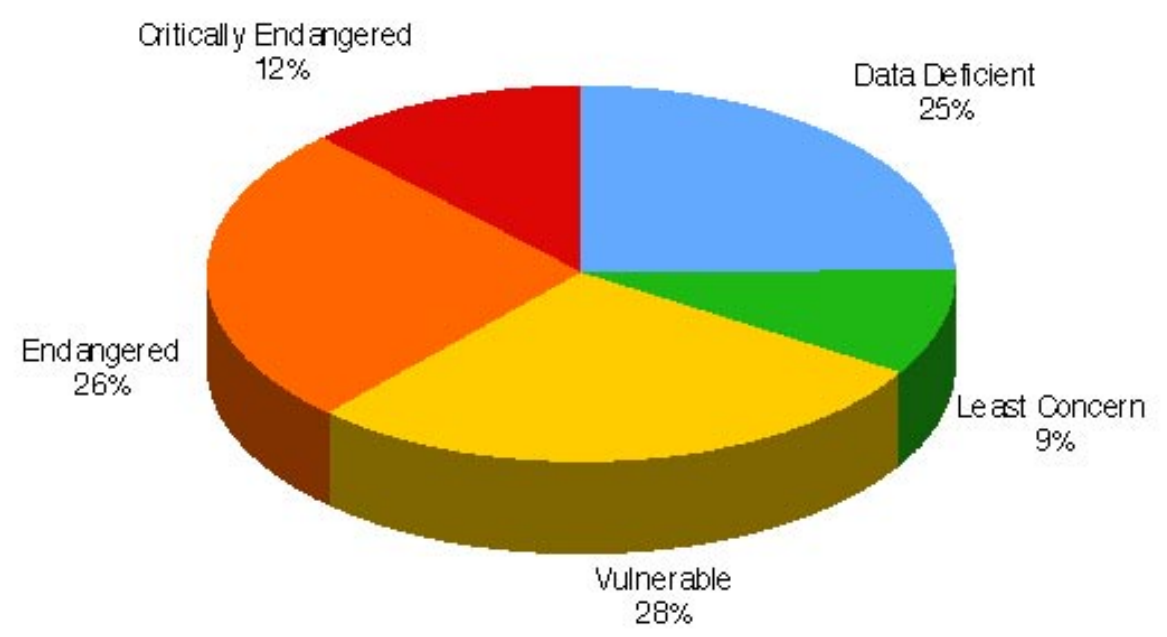

FIGURE 6. Conservation status of 65 lemur species according to IUCN categories (IUCN, 2001). Based on the Global Mammal Assessment workshop 2005 in Antananarivo organized by the International Union for the Conservation of Nature (IUCN) and Conservation International (CI).

\section{REFERENCES}

Andriaholinirina, N., Fausser, J.-L., Roos, C., Rabarivola, C., Ravoarimanana, I., Zinner, D., Thalmann, U., Ganzhorn, J.U., Meier, B., Hilgartner, R., Walter, L., Zaramody, A., Langer, C., Hahn, T., Zimmermann, E., Radespiel, U., Craul, M., Tomiuk, J., Tattersall, I., Rumpler, Y. (2006). Molecular phylogeny and taxonomic revision of the sportive lemurs (Lepilemur, Primates). BMC Evolutionary Biology 6(17) http://www.biomedcentral.com/1471-2148/6/17

Burney, D.A., Pigott Burney, L., Godfrey, L.R., Jungers, W.L., Goodman, S.M., Wright, H.T., Jull, A.J.T. 2004. A chronology for late prehistoric Madagascar. Joural of Human Evolution 47: 25-63

Cracraft, J. 1983. Species concepts and speciation analysis. Current Ornithology 1: 159-187

Curtis, D.J., Donati, G., Rasmussen, M.S. (eds.). 2006. Cathemerality. Folia Primatologica 77: 1-194

Donque, G. 1975. Contribution géographique à l'étude du climat de Madagascar. Nouvelles Imprimerie des Arts Graphiques, Paris.

Durbin, J.C. 1999. Lemurs as flagships for conservation in Madagascar In: New Directions in Lemur Studies, B. Rakotosamimanana, $\mathrm{H}$. Rasamimanana, J.U. Ganzhorn, S.M. Goodman (eds.), pp 269-281. Kluwer Academic/Plenum Publishers, New York.

Fleagle, J. G. 1999. Primate Adaptation and Evolution. Academic Press, New York.

Goodman, S.M., Benstead, J.P. 2003. The Natural History of Madagascar. The University of Chicago Press, Chicago.

IUCN (International Union for Conservation of Nature and Natural Resources). 2001. IUCN Red List categories and criteria: Version 3.1. IUCN Species Survival Commission, Gland (Switzerland) and Cambridge (UK)

Louis, E.E., Coles, M.S., Andriantompohavana, R., Sommer, J.A., Engberg, S.E., Zaonarivelo, J.R., Mayor, M.I., Brenneman, R.A. 2006. Revision of the mouse lemurs (Microcebus) of eastern Madagascar. Internationa Journal of Primatology 27: 347-389

MacPhee, R.D.E. 1994. Morphology, adaptations, and relationships of Plesiorycteropus, and a diagnosis of a new order of eutherian mammals. Bulletin of the American Museum of Natural History 220: 1-214.

Martin, R.D. 1972. Adaptive radiation and behaviour of the Malagasy lemurs. Philosophical Transactions of the Royal Society London B: 264: 295-352

Martin, R.D. 1990. Primate origins: a phylogenetic reconstruction. Chapman and Hall, London.

Myers, N., Mittermeier, R.A., Mittermeier, C.G., Fonseca, G.A.B., Kent, J. 2000. Biodiversity hotspots for conservation priorities. Nature 403: 853-858

Mittermeier, R.A., Tattersall, I., Konstant, W.R., Meyers, D.M., Mast, R.B. 1994. Lemurs of Madagascar. Conservation International, Washington DC.
Mittermeier, R.A., Valladares-Pàdua, C., Rylands, A.B., Eudey, A.A., Butinsky, T.M., Ganzhorn, J.U., Kormos, R., Aguiar, J.M., Walker, S. 2005. Primates in peril - The world's 25 most endangered primates 2004-2006. IUCN/SSC Primate Specialist Group and Conservation International, Washington DC

Mittermeier, R.A., Robles Gil, P., Hoffmann, M., Pilgrim, J., Brooks, T., Goettsch Mittermeier, C., LamoureuX, J., Da Fonseca, G.A.B. 2004. Hotspots revisited. Mexico City: CIMEX.

Mittermeier, R.A., Konstant, W.R., Hawkins, F., Louis, E.E., Langrand, O. Ratsimbazafy, J., Rasoloarison, R., Ganzhorn, J.U., Rajaobelina, S., Tattersall, I., Meyers, D.M. 2006. Lemurs of Madagascar. Conservation International, Washington DC.

Müller, A.E. and Thalmann, U. 2000. Origin and evolution of primate social organisation: A reconstruction. Biological Reviews 75: 405-435

Nowak, R.M. 1999. Walker's mammals of the world. The Johns Hopkins University Press, Baltimore and London.

Pastorini, J., Thalmann, U. and Martin, R.D. 2003. A molecular approach to comparative phylogeography of extant Malagasy lemurs. Proceedings of the National Academy of Sciences USA 100: 5879-5884

Petter, J.-J., Albignac, R. \& Rumpler, Y. 1977. Mammifères Lémuriens (Primates Prosimiens). ORSTOM/CNRS, Paris.

Schwarz, E. 1931. A revision of the genera and species of Madagascar Lemuridae. Proceedings of the Zoological Society London 1931: 399428

Tattersall, I. 1982. The primates of Madagascar. pp 382. Columbia University Press, New York.

Thalmann, U. in press. Biodiversity, phylogeogreaphy, biogeography and conservation: lemurs as an example. Folia Primatologica. 